This is an electronic reprint of the original article. This reprint may differ from the original in pagination and typographic detail.

Author(s): Vähäsantanen, Katja; Saarinen, Jaana

Title: $\quad$ The power dance in research interview. Manifesting power and powerless

Year: $\quad 2013$

Version:

Please cite the original version:

Vähäsantanen, K., \& Saarinen, J. (2013). The power dance in research interview.

Manifesting power and powerless. Qualitative Research, 13(5), 493-510.

https://doi.org/10.1177/1468794112451036

All material supplied via JYX is protected by copyright and other intellectual property rights, and duplication or sale of all or part of any of the repository collections is not permitted, except that material may be duplicated by you for your research use or educational purposes in electronic or print form. You must obtain permission for any other use. Electronic or print copies may not be offered, whether for sale or otherwise to anyone who is not an authorised user. 


\section{The power dance in the research interview: manifesting power and powerlessness}

\section{Katja Vähäsantanen \& Jaana Saarinen}

University of Jyväskylä, Finland

We examine the power that is manifested between interviewers and interviewees in research interviews. Our empirical examples are drawn from interviews conducted with (i) a vocational teacher and (ii) a senior researcher. We analysed the manifestations of power both in the course of the interviews and across interviews. We found that power is exercised and distributed diversely and situationally between the interview participants (interviewer and interviewee) during the interviews. It appeared that in a given interview, the interplay between individual backgrounds and the interview setting was connected to the activities through which power was manifested, and that these activities played a role in shaping the subsequent course and content of the interview. Our findings contribute to discussion concerning the shifting significance of difference and sameness between interview participants with regard to power relations, what is conveyed in interviews, and the manner in which it is conveyed.

Keywords: age, gender, interaction, knowledge production, power, profession, research interview

\section{Introduction}

Nowadays the research interview is recognized as an interactive practice in which knowledge, meanings and narratives are jointly produced by an interviewee and interviewer (Holstein and Gubrium, 2003; Kvale and Brinkmann, 2009; Riessman, 2008). In line with this, we consider the interview to be a site in which both interview participants affect what is constructed, and how the process unfolds. We are also aware that the relationship between interviewer and interviewee is increasingly conceptualized as a power relation (Kvale, 2006; Tanggaard, 2007), one that includes both creating togetherness and establishing differences (Ikonen and Ojala, 2007; Ramazanoğlu and Holland, 2002). In this paper we seek to contribute to discussion on the interview as a site of powered interaction, demonstrating aspects of the situationality and diversity of power during the course of interviews. Power is here understood to refer to the activities of interview participants which are directed towards reciprocally controlling the situation, and influencing the other person's actions and conversation. The exercise of power is seen as a two-way process, entailing discursive power as theorized by Foucault (1981). Through empirical examples, we shall illustrate activities through which power is variously exercised during interviews, indicating ways in which both 
interview participants can become less or more powerful within the interview. We shall also demonstrate that the manifestations of power are only partly related to interview settings or to formal power relations; thus we shall show that power is mainly intertwined with the subject's gender, age, and professional background.

\section{The research interview as powered social practice between interview participants}

The research interview is typically viewed as a specific institutional and instrumental form of conversation, with a clear power asymmetry between the interviewer and the interviewee. Kvale (2006) emphasizes that interviewers have a power position in terms of setting the stage and ruling the interview in accord with their research interests. For example, they determine the place and topic for the interview, initiate the interview, pose the questions, critically follow up the answers, and close the conversation. Indeed, the interview is traditionally seen as a one-way dialogue in which the role of the interviewer is to ask, and the interviewee to answer (Kvale, 2006; Holstein and Gubrium, 2003). However, the notion of the interviewer's exclusive power is only partly true. In reaction to the dominance of the interviewer, interviewees can withhold information, or talk about something other than what was asked for. They may also question the interviewers and oppose the interviewer's interpretations (Kvale, 2006; Kvale and Brinkmann, 2009).

Looking at the power in more detail, it has been suggested that the degree of control exercised by interview participants is related to the type of interview (Corbin and Morse, 2003; Fontana and Frey, 2005). Our concern here is with open-ended narrative interviews. In such unstructured interviews, interviewees have more control over the course of the interview than in structured interviews, particularly in terms of deciding what and how much they want to reveal (Corbin and Morse, 2003). However, interviewers have also control over the interview process, for example through active listening and asking questions (Corbin and Morse, 2003; Riessman, 2008).

If the exercise of power is connected to the traditional roles and hierarchies of the research interview, the characteristics of the participants can also be seen as entailing power positions. Gender has been noted as one such characteristic. In a review of the literature on women interviewing men, Schwalbe and Wolkomir (2003) argue that men often try to exert compensatory control over the interview situation through sexualizing, minimizing, and testing. Pini (2005) observed similar processes, with men performing their masculinity through emphasizing their heterosexuality, presenting themselves as powerful, and positioning themselves as knowledgeable in order to exert control over the female interviewer. Furthermore, Arendell (1997) reported situations in which men took charge, through instructing and questioning her. She also revealed that male interviewees' verbal and psychological interactions (for example via touching and sexual 
commenting) had made her feel unsafe. Overall, Arendell suggests that while the relationships between interview participants are contextually situated, they are nonetheless influenced by the identities and histories of the researcher and the researched alike. She also notes that gender incongruence may not function purely as a limitation on the interaction, since for men it can be more acceptable to discuss personal matters with a female than with a male interviewer (Arendell, 1997).

Studies on interpersonal dynamics have paid considerable attention to the position of women as both researchers and participants. Contemporary feminist researchers argue for the acknowledgement of power relations between women, and problematize the notion that matching along gendered identities automatically creates spaces of mutual understanding and equal interaction, as assumed in early feminist research methodology (Ikonen and Ojala, 2007; Ramazanoğlu and Holland, 2002; Reinharz and Chase, 2003). Current thinking is based on the notion that social attributes other than gender also mediate interpersonal dynamics. For example age, sexual orientation, and social status, plus the power positions these entail, enter into the interview situation to varying degrees (Ikonen and Ojala, 2007; Ramazanoğlu and Holland, 2002).

In examining the nature of the interview, Manderson et al. (2006) also found that the direction and content of a given interview was influenced by the context and setting of the interview (for example the time and place) and the social relationship between the interviewer and the interviewee (including age, class, gender, and linguistic style). Similarly, Broom et al. (2009) examined the influence of environmental, biographical, and psychosocial factors on the flow and content of interviews. The evidence suggests that such processes should not be viewed as unambiguous in their nature fashion: gender (for example) is neither inherently problematic nor beneficial (Broom et al., 2009). Although the studies mentioned above show the significance of various social and individual factors for the content and course of interviews, they do not demonstrate the importance of the interplay of the various factors pertaining to power within interviews, and how the same factor (for example gender) can be seen as both a resource for and a constraint on what is told within an interview. Thus, to understand better the complex and shifting nature of power, we here examine the manifestations of power that occur during the course of interviews, and how aspects of the settings and participants are together connected to power. We analyse interviews in which there are both differences and similarities between the interviewer and the interviewee, including their backgrounds.

The differences between interview participants have often been seen as problematic in terms of creating unequal power relations and discomfort (see Reinharz and Chase, 2003). In order to overcome differences and power inequalities, researchers can use different strategies, including 
self-disclosure, which takes place when the interviewer shares experiences and knowledge, answers questions, and expresses feelings (Fontana and Frey, 2005; Rapley, 2007; Reinharz and Chase, 2003). These activities can prompt rapport and encourage respondents to be more forthcoming in what they say. However, an interviewer's self-disclosure might also inhibit interview talk when it conveys the interviewer's greater entitlement to provide information about a particular topic (Abell et al., 2006).

Differences between the interview participants can also be seen as fruitful. Ikonen and Ojala (2007) argue that when researchers are not expert in the topics studied, or when they do not share similar experiences with interviewees because of their age, they are allowed to ask unauthorized or naïve questions. At the same time, a power relation can be divided: the interviewee can be an expert concerning the topic, and the interviewer can adopt a contrasting role, taking the position of a student. In other words, positioning plays a role in power relations and knowledge production. This means that how interview participants position themselves and each other, and how they respond to and perform such positions is part of the negotiation of meanings and power (see also Abell et al., 2006). Indeed various interaction styles and relations (including conflict, negotiation, and cooperation) can be seen as opportunities, but also as different grounds for the production of knowledge (Enosh and Ben-Ari, 2010). Overall, although there has been discussion of the differences and similarities between interview participants, there is still much to learn about their contradictory meanings for actualizing power and producing knowledge within a research interview.

\section{The research process}

\section{Aims of the study}

The present paper addresses the manifestation of power between the interviewer and the interviewee during the course of research interviews. Our aims are (i) to demonstrate how the interviewer and interviewee exercise and present power within interactive relationships, and (ii) to examine the kinds of strands that are intertwined with the manifestations of power observable between interview participants.

\section{Interviews and participants}

We draw on open-ended narrative interviews from two sub-studies aimed at understanding subjects' professional identities, agency, and careers (Vähäsantanen et al., 2008, 2009). In her study, Katja interviewed sixteen vocational teachers (ten men and six women, aged 31-57, with teaching experience varying from 4 to 30 years); the teachers were teaching in various fields in a single vocational institution. In the study by Jaana, the interviewees were seven women researchers (aged 
36-48) from different universities. In both of these sub-studies, participation was voluntary. The interviews were recorded, and Katja also wrote field notes on the interviews.

From the data sets, we selected two interviews in line with the aims of our present study. These interviews were conducted with a vocational teacher (here called Elias), and with a senior researcher (here called Lisa). Table 1 summarizes the details concerning the interviews. We selected these interviews as par excellence examples, since they were informative, and encompassed various perspectives on power within interviews (involving interview settings and individual backgrounds, in particular age, gender, and profession). However, although they stood out to some extent in our interviews, many similar aspects could be found in the other interviews. For example, the positioning of a researcher on the basis of age and gender occurred in other interviews conducted by Katja. We also selected interviews that were quite different from each other, in order to illustrate the differences and complexities related to power as they emerged across interviews.

Table 1: Details of the interviews

Katja interviewing Elias Jaana interviewing Lisa

The interviewer

The interviewee

Previous relationship

Place

Duration
Katja: aged 25, woman, doctoral student

Elias: aged 52, man, experienced vocational teacher

Unknown to each other

The meeting room at Elias's institute

2 hours 5 minutes
Jaana: aged 44, woman, $\mathrm{PhD}$, researcher.

Lisa: aged 44, woman, $\mathrm{PhD}$, senior researcher

Jaana had read Lisa's publications

Lisa's office at the university 1 hour 30 minutes

\section{Analytical tools}

We utilized narrative approaches to analyse the manifestations of power, as they appeared both in the course of interviews and across interviews (Lieblich et al., 1998; Riessman, 2008). In the first phase of the analysis, the transcript interviews were analysed holistically from case to case. The purpose was to search for certain themes and patterns related to the aim of the study, and also to identify shifts in the manifestations of power within the interviews. We therefore proceeded via a search for the most illustrative episodes in which power was manifested in our data, seeking also to 
identify the different factors which seemed to be related to power. In the second phase of the analysis, we compared the differences and similarities between the interviews selected. All in all, the findings and conclusions were reached through abductive (including both inductive and deductive) interpretation (Patton, 2002). Hence, power was examined on a data-driven basis, through analysis of the contents of the interviews. Nevertheless, our theoretical foundation also influenced the way the analysis was conducted. In the following sections, the manifestations of power observable in the interviews with Elias and with Lisa are presented separately, moving from one interview to another. The first episode uses a combination of the transcribed interview and field notes; all the other examples are from the interview transcriptions.

\section{Katja interviewing Elias}

This section has four parts. The first part illustrates how power asymmetry was created through questioning and instructing the researcher at the start of the interview. The second part focuses on different actions taken to control situations in the interview process. The third part illustrates the negotiation of power and of the issues discussed; it includes the sexualizing of the researcher and the way of reacting to this action. The fourth part encompasses the taking and balancing of power by the interviewee at the end of the interview. In all the parts, there are illustrations of how individual backgrounds (age, gender, and profession), and interview settings (practices, motives, and presuppositions related to the interview) shape the use of power.

\section{Questioning and instructing the researcher at the start of the interview}

Traditionally, it has been suggested that interviewers have power at the beginning of the interview. They set the stage for the interview, ask permission to record, re-explain the purpose of the interview, and give information about confidentiality (Kvale, 2006; Rapley, 2007). This initial period is also a time when the interview participants assess each other and begin to establish a degree of reciprocity (Corbin and Morse, 2003). At the start of Elias's interview, the atmosphere was not convivial and the interviewer did not control the direction of the conversation. In fact, Elias (the interviewee) exercised power through questioning Katja's choice of work as a researcher (expressing also disapproval of researchers in general), and instructing her on how to do research. The episode described below illustrates how this power asymmetry was created:

Katja and Elias introduced themselves, and Elias talked about his work. Then Elias, having observed that Katja had already got her Master's Degree, came out with 'Why do you need to get a PhD when you are so young, why are you in such a hurry?' Then he went on to say that researchers live in a world of their own, in their own researchers' cells, and that they don't 
have any grasp of practical work. Katja commented, saying, 'But here I am now, out in the field.' But Elias just continued, 'But researchers have tunnel vision, they've got blinkers over their eyes.' Then Elias asked about her research in more detail. At this stage Katja told him about the recording and introduced her research. Katja also told him that she would interview in total sixteen vocational teachers from his vocational institution. Elias commented, 'Okay, but a rather larger sample would be better.' Katja agreed with him. Then Katja explained the confidentiality aspect and introduced the topics to be included in the interview.

She then presented the actual 'opening question'.

In this extract we can see how Elias immediately broke with the traditional interview frame and the role of the interviewee as the respectful informant who questions neither the research work nor the professional identity of the researcher (see also Arendell, 1997, Tanggaard, 2007). Here, it seems that Katja's young age and her profession were factors that to a large extent denied her respect or power. On the basis of these factors together, Elias positioned her and took power; hence Katja was immediately put at a disadvantage, contrary to the common view that the academic position of researchers gives them a degree of power over the interview situation (Corbin and Morse, 2003).

The example also demonstrates how Katja was a fairly passive actor who briefly tried to justify herself, but unprotestingly accepted the position she was offered as an ignorant researcher. Similarly, Katja accepted Elias's advice on her research, although as a researcher she probably had more knowledge of research. This passiveness was mainly connected to the fact that Katja was confused, since she had not anticipated that this kind of episode would occur (cf. Sands and Krumer-Nevo, 2006). However, amid all the criticism and instructions Katja was an active actor, adhering to the position of a researcher and seeking to carry out research duties related to the initial stage of an interview, such as dealing with confidentiality.

\section{The struggle for control in the process of the interview}

The interviewer as questioner, the interviewee as teller. During the interview Katja asked questions based on her research interests and sought clarifications; thus, in her role as interviewer she exercised power in terms of directing the conversation. Schwalbe and Wolkomir (2003) suggest that men who are interviewed by a female researcher may refuse to give expansive answers, instead offering terse answers (i.e. minimizing), in order to protect their masculine self by maintaining control. In the interview with Elias, the strategy of maximizing was more in evidence in the assertion of control, since Elias's answers were typically extremely long. He also used power in terms of neglecting the questions asked, chatting generally, and talking about the issues he wanted to bring up (Corbin and Morse, 2003; Kvale, 2006). Enosh and Ben-Ari (2010) use the terms 
deflection and power games, referring to situations in which the interviewee ignores the questions of the researcher by changing the subject to seemingly irrelevant issues. This can be seen as sidetracking the interview process.

In the course of the interview, Elias also talked openly about his personal concerns. The next episode shows how such open disclosure occurred, illustrating his desire to talk about his life and himself. Thus, Elias had the power to direct the conversation, although in this situation Katja also followed up his answer, directing him towards discussion of personal resources amid ongoing changes - aspects that were in the line with her research interests.

Katja: Is it difficult with regard to that constant change?

Elias: No. Just so long as there is enough time and your nerves hold out, that's all.

Katja: But the time and resources weren't taken into consideration that well back then.

Elias: Indeed, it takes resources [to work amid continuous changes]. A while ago I was on sick leave because of burn-out at work, a touch of depression. Or let's say that it was the last straw when my mother died, and it's always a big issue in families with children... That burnout at work had been developing over the years and then it was the last straw, my strength just gave out.

When Elias talked about his personal affairs, Katja was a listener, since she had not had similar personal experiences or feelings that she could share. However, Elias was willing to share his experiences, despite the differences in the backgrounds of the participants. One could say that Elias saw the interview as a chance to disclose things, positioning Katja as a trustworthy person. Indeed, Elias's motives seemed to play an essential part in open disclosure (Corbin and Morse, 2003) though one could speculate that the interviewer's gender might also have been a factor promoting this openness (Arendell, 1997).

Testing and instructing by the interviewee. Within the interview, the talk did not consistently follow the standard format of questions asked by interviewer plus answers provided by the interviewee (Holstein and Gubrium, 2003; Kvale, 2006), since Katja became positioned by Elias in the role of respondent. One interpretation of this would be to see it as a way of bringing the interviewer into the discussion. However, Katja had the impression that Elias was trying to test her, and that she had to answer the questions correctly and display her knowledge after the questioning by Elias at the start of the interview (cf. Ikonen and Ojala, 2007). To a large extent we would agree with Corbin and Morse (2003), who argue that the initial moments tend to set the tone for the forthcoming interview.

During the interview, Elias also instructed Katja about his vocational field. For example, at one point he said, 'I'll give you the journal, and you can read one article. It isn't a big thing, just so 
that it would change the attitude towards this kind of good material.' This happened even though Katja had not criticized Elias's vocational field in any way. It is possible to interpret Elias's way of asking and educating Katja as being related to his profession. He was a teacher, and this kind of posing of questions and instructing can be seen as a typical way for teachers to communicate. Thus, we could assume that Elias acted in the position of a teacher, seeing Katja as having the position of student, a perspective which emphasized power asymmetry. On the other hand, the instructing could be also seen as related to the gender of the interviewer. It has previously been noted that it is fairly typical for men interviewed by women to take control of the interview by instructing (Arendell, 1997), and to position the female interviewer as innocent and slightly dim; in so doing, the interviewee may adopt the tone and manner of a teacher/father (Pini, 2005).

\section{Negotiation of power and issues discussed: sexualizing the researcher and reacting to this action}

During the interview, Elias positioned Katja as a young woman and as a potential date. This is presented in the next extract, as are the changes that occurred in power relations through the active actions of both interview participants. In fact, the extract shows how Katja initially used power, since it begins with a question from Katja inviting Elias to talk about his experiences. In his response Elias took power through not answering a question. He then moved the discussion away from the interview frame through wondering about the possibility of a date. This can be seen as an act of sexualizing the interlocutor, and also as a moment in which heterosexuality emerged. The extract further demonstrates how Katja exercised power through reacting to this, and how she managed to return the conversation to the interview frame.

Katja: How do you find the speed of the changes, when things are being brought in such as vocational skills demonstrations and more workplace learning?

Elias: Yes, that's it, really. I've always compared the current situation to the situation when I attended vocational school, 34 years ago. You aren't so old yet, you've at least ten years to go till you get to that point. Still, I could very well go on a date with you, at least from my point of view. I don't know, what do you think?

Katja: So maybe we could go to over to the café after this interview.

Elias: So... [pause]. So, so, when I was a student we had two classes and I think that there were thirteen students in both classes and nowadays...

In the present case, the interplay of age and gender seems to be essential in the processes of positioning the researcher. The motives Elias may have had in making this proposal remain unclear. Perhaps it was testing, or making an innocent comment, or posing a humorous question - or perhaps in some way expressing real thoughts. 
Generally, sexualizing, which can take the forms of flirting, sexual innuendo, and remarks on appearance, has been seen as a way in which men try to reassert control when they are interviewed by women (Arendell, 1997; Schwalbe and Wolkomir, 2003). All this can disrupt the interview process. In the present case, however, Katja's comment returned the discussion to its matter-of-fact course. Elias's suggestion did indeed surprise Katja; she had not imagined beforehand that something like this could take place in the interview (cf. Sands and Krumer-Nevo, 2006). However, she reacted spontaneously and humorously: 'So maybe we could go to over to the café after this interview.' In this situation, Elias seemed to be surprised when - as compared to the previous exchanges - Katja commented more actively and less academically. She distanced herself from the researcher role and played with the rules concerning the 'sexual interactional tone' determined by Elias. Indeed, Katja was here fairly active and resisted the exercise of power by Elias. We can also see that in a sense Katja made a point - that the immediate context was an interview context, and that personal issues belonged outside the interview - by her response. Interviewers can adopt different strategies in response to forms of sexualizing (Arendell, 1997; Schwalbe and Wolkomir, 2003), but Katja's answer functioned here as a considered reaction, since it directed Elias to answer the question relevantly. All this demonstrates how the interview includes negotiations concerning control and the issues to be discussed. It also exemplifies how the activities of both participants shape power relations, and the contents of the interview.

\section{The taking and balancing of power by the interviewee at the end of the interview}

During the interview, Elias assigned shifting positions to the interviewer, including those of researcher, young woman, and trustworthy listener. Seeing the researcher in a different light could occur within the same stretch of speech. For example, at the end of interview Katja asked how Elias saw his future. Elias then started to talk about how his future would be lovely if he was married to Katja, and after this he continued directly with talk about his personal affairs and future fears, without any input from Katja.

After Elias's talk of his future, it was to some extent Elias who proposed the closing of the interview, although it is usually the researcher who takes this role (Kvale, 2006; Rapley, 2007). This occurred in the form of a question to Katja, asking whether she had been able to ask about everything she wanted. Katja, at least, evaluated the question this way, since she then moved to the question ('Would you like to add anything?') which many researchers ask at the end of an interview (see extract below). Thus we can think that Elias took on himself the power to close the interview. This was totally acceptable to Katja after over two hours of conversation.

Elias: ... [answers Katja's question]. So, were you able to ask all you wanted to ask? 
Katja: Yes. Would you like to add anything?

Elias: I could say one thing. When I came in, I thought it was a vocational school student who was sitting here. Yeah, you looked like a student with your bag. I wondered if this little lass was really someone with a Master's Degree, doing a PhD thesis. But it's a great thing.

Katja: And thank you for taking part in the interview.

Elias: You're welcome. I'd say that we always need to promote research and maybe we also get some benefit from it... Let me know when you defend your dissertation.

Katja: Yes. And will you be around if we could meet up again in the spring and talk?

Elias: Yes, I'll certainly be here.

In this extract we can also notice how Elias talked about his initial interpretation of the interviewer, which was connected with Katja's age and appearance. Although Elias's initial thoughts seemed derogatory in terms of age and gender, in a sense Elias now gave professional respect to Katja, because she was doing her $\mathrm{PhD}$. In addition to this, Elias no longer described researching as useless. All this showed a contrast with the initial moments of the interview, when he questioned Katja and criticized researchers.

When we become aware of Elias's initial thoughts concerning the interviewer and his later evaluation of research, we can consider that his initial actions might be a consequence of his confusion, since his stereotypes of researchers (in terms of gender and age) were not realized when he met Katja, who looked like a young student. Elias's surprise might be also related to his generation; in the past, especially for young people, it was not so common to study for a $\mathrm{PhD}$. In a way these interpretations would make sense, since at the end he wanted to talk about his initial thoughts and perhaps give excuses for his way of talking. Of course, it also might be that at the beginning of the interview he presented his actual opinions, and that he really wanted to take control of the interview situation. In a way Elias's actual motives do not matter. Rather, the significance is that Elias's actions at the beginning of the interview created a power asymmetry, and further influenced the interactions in the interview.

\section{Jaana interviewing Lisa}

This section is divided three parts. The first part illustrates how interview participants may take power and relinquish it at the start of an interview. In the second part, collective knowledge production is addressed from the viewpoint of power relations. The third part demonstrates the process of negotiating contradictory positions during the interview. In all the parts, one can also see that power is used in relation to individual backgrounds - in particular personal history and 
professional background - and also to interview settings (practices, motives, and presuppositions related to the interview).

\section{Taking power and relinquishing it at the start of the interview}

At the initial period of the interview, the atmosphere was convivial and comfortable, including general discussion about the interview topic (Corbin and Morse, 2003). In the initial phase of the interview, the participants also negotiated some practical matters, such as recording the interview (Corbin and Morse, 2003; Rapley, 2007) and the timetable. In connection with the negotiation of the timetable, as the next extract shows, Lisa told Jaana about her children. In this situation, Jaana tried to create a sense of sameness through sharing the mother position. This can be seen as an act of self-disclosure (e.g. Reinharz and Chase, 2003). But instead of sharing more of her personal background, Lisa cut off the discussion by remarking on the timetable and thus directing the conversation strictly to the interview frame, as the start of the extract illustrates:

Lisa: ...I have a little girl. It's always nice that she phones me if she's changing her plans.

Jaana: Yes. How old she is?

Lisa: Ten years old, and my son is a few years older.

Jaana: I have a nine-year-old son, he has his tenth birthday in July.

Lisa: Okay, let's make a start. As I mentioned to you earlier our department meeting starts at two o'clock.

Jaana: You'll have to keep an eye on the time, for I have the time here and not here (Jaana shows the recorder on the table, and points to her wrist.)

Lisa: Yes, let's do it that way.

Jaana: Yes, we could start this interview about.... or you can choose - where do you want to start the story? How could you describe your starting points or choices on the path to becoming a researcher? Or how did you become interested in research work?

Lisa: Do you think I should begin at very beginning, before the doctoral thesis?

Jaana: Yes, you can start to tell your story there.

By switching the topic and separating herself from the mother position, Lisa rejected the interviewer's attempt to create a sense of sameness, and controlled the direction of the interaction. At the same time, she emphasized that the aim of the interview was to concentrate on the topic of the research rather than to chat generally. In a sense, Lisa had a precise focus and certain presuppositions related to the interview, and the interviewer's self-disclosure was unnecessary (cf. Reinharz and Chase, 2003). 
As we can see in the latter part of the extract, Jaana asked Lisa to take responsibility for the time taken for the interview. Traditionally it is seen as the task of the interviewer to control the conversation (Holstein and Gubrium, 2003; Kvale, 2006). Thus, in a sense, Jaana gave power away here, but then regained the interviewer position, posing the opening question related to her interview agenda. By using an extensive set of questions, Jaana give power to Lisa to decide where to start her narrative, without setting strong limitations on the telling. In the absence of a clearlyfocused question, Lisa avoided the power position, asking Jaana to clarify where she should start her story. We could surmise that Lisa wanted to be sure that the telling was relevant to the research being conducted; after all, having a tight schedule, she did not wish to spend time on unnecessary matters. Overall, the episode above highlights the fact that power positions can shift between the interview parties during the interview process, and that it is not only interviewers who control the time and ask questions.

\section{Collective knowledge production in specific power relations}

Telling a story and self-disclosure by interview parties. Although Lisa had successfully climbed up the academic ladder, at the time of the interview her possibilities for continuing her academic career were in the balance. This was due to the fact that there are many qualified senior researchers holding the position of docent, all of whom are competing for decreasing funding and a small number of jobs. When Lisa talked about her insecure career, Jaana presented some figures on postdoctoral research places from the position of a research coordinator (her previous profession). Her aim was to emphasize that many researchers were in the same position as Lisa.

Here, Jaana displayed her knowledge of the topic discussed - a strategy of self-disclosure which she employed in preference to other possible self-disclosure strategies, such as sharing her experiences (Fontana \& Frey, 2005; Rapley, 2007). In this situation, it would have been possible for Lisa to interpret this as an act of making a distinction - i.e. she might see Jaana as seeking to take on the position of a higher expert, someone with wide knowledge and the entitlement to talk about the topic (Abell et al., 2006). This might have functioned as a constraint on Lisa's telling. However, Lisa did not interpret the use of Jaana's professional background as a tool for dominance. This interpretation arises from the fact that after Jaana disclosed her knowledge, Lisa continued with her account in a forthcoming manner. Furthermore, Lisa and Jaana together analysed the current situation in academia, and discussed its consequences for female researchers. In fact, at this point the participants created a relationship in which they shared views and created collective meanings from similar professional backgrounds (Reinharz and Chase, 2003).

The cooperative negotiation of interpretations. During the interview, knowledge production 
related to the topic of the interview also occurred in other situations. The next episode illustrates an example of collective knowledge production, including the offering of a framework for interpretation by the interviewer, and acceptance of this by the interviewee. This feature occurred when Lisa talked about her current work situation and her career prospects.

Lisa: I've done just about okay [regarding what a post-doctoral researcher is expected to do], but I don't know if I've a future in the academic world. At the moment I'm supervising five doctoral students, doing it more or less for free, in other words doing the work of a professor. And I'm not the only one, I'm pretty typical here, and now I can't say... But there are a whole lot of us women in this situation...

Jaana: I just came to think of it, that idea in a way, whether it was the case, when you said there were many women who were docents. Whether that supervising work was some kind of invisible work done by women. I mean work in a way without payment. Are these supervised students you've got officially registered as being supervised by you?

Lisa: Yes, they are.

Jaana: I know that there are a lot of people supervising without their names being written down [officially] anywhere.

Lisa: Yes, my name is on a piece of paper, but still it's in many respects invisible work, of course I don't get up on a platform and chair thesis defences, because I'm not the professor. So I think that's a really, really good question. It's as if that supervising work was gradually becoming one of these areas of women's invisible work. You know? Yet it has traditionally been one of the most highly-regarded jobs in the university, supervising doctoral students. So it's an utterly hopeless situation.

This example shows how Lisa highlighted the fact that she was not the sole woman who was supervising doctoral student more or less for free. Jaana followed Lisa's talk closely (Corbin and Morse, 2003; Kvale and Brinkmann, 2009) and as a reflective listener provided the phrase 'invisible work done by women' as a framework for interpretation of this situation, responding to Lisa's talk.

According to Kvale and Brinkmann (2009), the interpreting of interviewee talk by the interviewer is a part of interviewing. It means that the interviewer clarifies and extends the meanings of the interviewee's statements, providing interpretations of what is said. These may then be confirmed or disconfirmed by the interviewee, which can be seen as an act of power. In the situation presented here, Lisa accepted the interpretative framework offered and continued to analyse docents' work in detail, as unpaid and invisible women's work. Thus, this example demonstrates how the interview is not an interviewee monologue recorded by an interviewer, but a co-constructive process involving the active presence and contribution of both actors (Holstein and 
Gubrium, 2003; Kvale and Brinkmann, 2009). The offering of the interpretative framework here created a platform for jointly creating knowledge - though it might have been interpreted by the interviewee as a display of the interviewer's power position, tending thus to suppress further talk (Abell et al., 2006).

\section{Negotiating contradictory positions in the interview process}

Although collective knowledge production occurred in the interview with Lisa, the interaction was also contradictory at times. It is easy to see that the research interview can be a context in which the contradictory assumptions and discourses of the research topic meet each other, and are challenged or ignored (Tanggaard, 2007). The following example involves negotiation in which one can see the offering of a position and interpretation by the interviewer, plus the interviewee's refusal to accept this position. At the start of the extract Jaana agrees with Lisa concerning researchers:

Jaana: Yes, yes, they seem so astonishing, these incredible stories. Because it's common for researchers working on a grant not to have an office in the department and to have to go somewhere 'out in the street'.

Lisa: Yes, yes... But I'm a member of the departmental management group, and of course I've been teaching for many years, and I have that research project that's being done here, I have various connections, but for example I don't get a salary myself [from the projects or the department]. It also means that I don't have any insurance or occupational health care, or the things that the people I'm supervising get.

One can see that in this episode Jaana offered Lisa the position of an outsider in the department, a person who can lose her office and 'end up on the street'. In this situation, Jaana distanced herself from the role of questioner, and tried to conceptualize Lisa's situation from a new perspective. In a sense, Lisa could be seen as an outsider occupying the 'outer circle', since she was working on a grant, and had no current appointment with the university. In her response, Lisa exercised power through refusing to accept this position; she highlighted as arguments her long-term working relationship with her department, and her various connections with the department.

Lisa initially disagreed with Jaana's rather pessimistic perspective on the grant-funded researchers' situation (Tanggaard, 2007). However, at a later stage of the interview, Lisa admitted to being in some respects a member of the 'outer circle', and she talked about her current situation using this term. To put it in another way, through offering a certain position, the interviewer provoked further interview talk; however, this occurred through disagreement and further consideration by the interviewee rather than through passive adaptation. In this case, we would suggest that when a different view was encountered, Lisa started to reflect on and conceptualize her 
situation from a new perspective. The general point here is that through sharing opinions and interpretations it is possible to view one's position in a new way and to gain a new understanding of the self (Holstein and Gubrium, 2003; Riessman, 2008).This means that it is not always beneficial for knowledge production that the interview participants have totally similar backgrounds, or views on the topics discussed (Enosh and Ben-Ari, 2010; Tanggaard, 2007).

Although Lisa and Jaana had different views on particular issues, at the end of the interview it became clear that they shared similar presuppositions regarding the interview, when they disclosed motives related to the interview. In particular, they wanted to use the interview to contribute to discussion on women researchers' experiences of academic life. After this, and after Lisa talked about her future, Jaana closed the interview by asking, 'Would you like to add anything?' Lisa agreed that it was time to close the interview.

\section{Manifestations of power between interviewer and interviewee}

The interviews presented showed various activities through which power appeared, see Table 2. These activities came up in diverse ways within and across the interviews.

Table 2: Activities related to exercising and presenting power

\section{Power-related activities}

Interviewer Deciding the topic and issues to be discussed

Asking questions and seeking clarifications

Closing the interview

Responding to positions offered and control exercised by the interviewee

Offering positions and interpretative frames to the interviewee

Self-disclosure through sharing personal and professional backgrounds

Interviewee Answering, giving his/her account, and deflecting questions

Asking questions and seeking clarifications

Controlling the use of time and closing the interview

Offering positions

Responding to positions, to self-disclosure, and to interpretative frames offered

Testing, instructing, and questioning the interviewer

Sexualizing the interviewer 


\section{Concluding remarks on power in the research interview}

The study illustrates the complexity and situationality of power during interviews. Power takes many forms, and in the course of the interview it shifts back and forth between the interviewer and the interviewee. Indeed, both interview participants use power, but are, in certain respects, powerless. The findings further indicate that individual backgrounds (gender, age, professional background, and personal history) and the settings of a given interview (the interview parties' motives and presuppositions regarding the interview, plus the interview practices) are together intertwined with activities through which power appears, with each of these activities further playing a role in shaping the course and content of the interview (cf. Arendell, 1997; Kvale, 2006; Kvale and Brinkmann, 2009).

Although power is manifested discursively in our interview examples, the exercise of power is also related to non-discursive aspects. Through self-disclosure it is possible to elicit 'invisible' aspects of subjects' backgrounds (e.g. professional knowledge); this can further shape the power relations and contents of interviews. Furthermore, interview roles and frames are part of the exercise of power referable to as formal power - yet the boundaries of formal power relations can also be breached. In such cases, we found that power-related activities were often interwoven with the interview participants as persons with their embodied characteristics. For example, Elias as the interviewee used power over the interviewer by foregrounding her age and gender, and in so doing, he sexualized the interviewer. In these kinds of situations, interviewers are fairly powerless, since age and gender cannot be concealed, although it is also true that they can decide how actively or passively they respond to such power-related activities (cf. Arendell, 1997). Indeed, if the interview is to be worthwhile, interviewers must adapt their responses and activities in such a way as to match the interview context with the interviewee. The interviews presented here further indicate that the participants' motives and presuppositions regarding the research setting were present in the background of the interview. When the preconceptions of the interviewee and interviewer (concerning the research and the other participant) were not realized, the participants were surprised, and they reacted in different ways to these surprising situations (cf. Sands and Krumer-Nevo, 2006). Since more or less anything can happen in a research interview, as demonstrated here, an important characteristic of interviewers is to be able to react quickly and flexibly to unexpected situations (Kvale and Brinkmann, 2009).

In our study, it seemed that substantial differences between the interviewer and the interviewee created an arena for using and presenting power strongly and diversely. This unfolded in the interview with Elias in particular, with age and gender playing important roles. Yet these factors need not be inherently limiting or problematic. We suggest this on the grounds that despite 
the differences in the backgrounds of the participants illustrated here, the discussion proceeded openly. In this sense, a strong degree of sameness between the interviewer and the interviewee is not a prerequisite for the production of narratives. It is true that sameness between the interview participants (having similar experiences and the same gender) seemed to enable more equal relationships between them, and to create a platform for shared knowledge production. Yet the interview with Lisa indicated that even when there is sameness, the interview parties do not by definition share similar interpretations - while also indicating that differences of this kind can be fruitful for creating knowledge (Enosh and Ben-Ari, 2010). All in all, we suggest that the actual differences and similarities between the interview actors do not, in themselves, shape the power dynamics, or the progress and content of interviews. Rather, what matters is how the differences and similarities are produced and presented, based on the participants' situational interpretations of each other and of their utterances during the interview. Thus, it is important to be aware of the similarities and differences between participants, but there is no need to minimize these differences.

The power manifested in the research interview has here been addressed in relation to the actual interview process. But power also exists after the interview (Reinharz and Chase, 2003). As researchers, we have here used power in analysing and reporting our interpretations of the power exercised in the interviews. These interpretations could diverge from the interviewees' own interpretations concerning the interview situation and their own actions. In fact, it would be interesting to study power relations and activities by asking both the interviewee and the interviewer about their feelings and opinions - regarding the interview situation, their own actions, and the actions of the other party - directly after the interview. Despite this interesting possibility, we take the view that in relation to the course and content of the interview, more important than any (postinterview) 'true' explanations is an understanding of how the actions of others are interpreted during the interview, and how these interpretations shape the parties' activities and power relations.

\section{References}

Abell, J., Locke, A., Condor, S., Gibson, S. and Stevenson, C. (2006) 'Trying Similarity, Doing Difference: The Role of Interviewer Self-disclosure in Interview Talk with Young People', Qualitative Research 6(2): 221-244.

Arendell, T. (1997) 'Reflections on the Researcher-researched Relationship: A Woman Interviewing Men', Qualitative Sociology 20(3): 341-368.

Broom, A., Hand, K. and Tovey, P. (2009) 'The Role of Gender, Environment and Individual Biography in Shaping Qualitative Interview Data', International Journal of Social Research Methodology 12(1): 51-65. 
Corbin, J. and Morse, J. M. (2003) 'The Unstructured Interactive Interview: Issues of Reciprocity and Risks when Dealing with Sensitive Topics', Qualitative Inquiry 9(3): 335-354.

Enosh, G. and Ben-Ari, A. (2010) 'Cooperation and Conflict in Qualitative Research: A Dialectical Approach to Knowledge Production', Qualitative Health Research 20(1): 125-130.

Fontana, A. and Frey, J.H. (2005) 'The Interview: From Neutral Stance to Political Involvement', in N.K. Denzin and Y.S. Lincoln (eds) Handbook of Qualitative Research (3rd Edition), pp. 695727. Thousand Oaks, CA: Sage.

Foucault, M. (1981) 'The History of Sexuality'. Harmondsworth: Penguin Books.

Holstein, J.A. and Gubrium, J.F. (2003) 'Inside Interviewing: New Lenses, New Concerns', in J.A. Holstein and J.F. Gubrium (eds) Inside Interviewing: New Lenses, New Concerns, pp. 3-29. Thousand Oaks, CA: Sage.

Ikonen, H-M. and Ojala, H. (2007) 'Creating Togetherness and Experiencing Difference in Feminist Interviews: Knowing in a Post-standpoint Way?', Graduate Journal of Social Science 4(2): 80102.

Kvale, S. (2006) 'Dominance Through Interviews and Dialogues', Qualitative Inquiry 12(3): 480500.

Kvale, S. and Brinkmann, S. (2009) Interviews: Learning the Craft of Qualitative Research Interviewing. Thousand Oaks, CA: Sage.

Lieblich, A., Tuval-Mashiach, R. and Zilber, T. (1998) Narrative Research: Reading, Analysis and Interpretation. London: Sage.

Manderson, L., Bennett, E. and Andajani-Sutjahjo, S. (2006) 'The Social Dynamics of the Interview: Age, Class, and Gender', Qualitative Health Research 16(10): 1317-1334.

Patton, M.Q. (2002) Qualitative Research \& Evaluation Methods (3rd Edition). Thousand Oaks, CA: Sage.

Pini, B. (2005) 'Interviewing Men. Gender and the Collection and Interpretation of Qualitative Data', Journal of Sociology, The Australian Sociological Association 41(2): 201-216.

Ramazanoğlu, C. and Holland, J. (2002) Feminist Methodology. Challenges and Choices. London: Sage.

Rapley, T. (2007) 'Interviews', in C. Seale, G. Gobo, J.F. Gubrium and D. Silverman (eds) Qualitative Research Practice, pp.15-33. London: Sage.

Reinharz, S. and Chase S.E. (2003) 'Interviewing Women', in J.A. Holstein and J.F. Gubrium (eds) Inside Interviewing: New Lenses, New Concerns, pp. 73-90. Thousand Oaks, CA: Sage.

Riessman, C.K. (2008) Narrative Methods for the Human Sciences. Thousand Oaks, CA: Sage. 
Sands, R.G. and Krumer-Nevo, M. (2006) 'Interview Shocks and Shockwaves', Qualitative Inquiry 12(5): 950-971.

Schwalbe, M.L. and Wolkomir, M. (2003) 'Interviewing Men', in J.A. Holstein and J.F. Gubrium (eds) Inside Interviewing: New Lenses, New Concerns, pp. 55-71. Thousand Oaks, CA: Sage.

Tanggaard, L. (2007) 'The Research Interview as Discourses Crossing Swords: The Researcher and Apprentice on Crossing Roads', Qualitative Inquiry 13(1): 160-176.

Vähäsantanen K, Hökkä P, Eteläpelto A, Rasku-Puttonen H and Littleton K (2008) 'Teachers' professional identity negotiations in two different work organisations'. Vocations and Learning: Studies in Vocational and Professional Education 1(2): 131-148.

Vähäsantanen K, Saarinen J and Eteläpelto A (2009) 'Between school and working life: vocational teachers' agency in boundary-crossing setting'. International Journal of Educational Research 48(6): 395-404. 